\title{
Comparative Effects of Circuit Training Programme on Speed and Power of Pre- and Post- Menarcheal Girls
}

\author{
Adeniji, B. A. \\ Physical and Health Education Department, \\ Federal College of Education, Osiele, Abeokuta, Ogun State, Nigeria
}

\begin{abstract}
This study examined the Comparative Effects of Circuit Training Programme on Speed and Power of Pre- and Post-Menarcheal girls. A pre-test- posttest control group experimental design was used to carry out the study. A total of 80 Secondary School girls from St. Peter's College, Olomore, Abeokuta, in Ogun State of Nigeria, ages 10-17 years took part in the study. The subjects were not involved in competitive school sports. Stratified random sampling technique was used to select 40 pre-menarceal and 40 postmenarcheal girls who were later randomly assigned to experimental and control groups. At the end of the training programme, 40 subjects completed the post training measurements, so there were 10 subjects in each of the four study groups (pre-menarcheal experimental, pre-menarcheal control, post-menarcheal control, post-menarcheal experimental, postmenarcheal control groups). The data collected were subjected to descriptive statistics of mean and standard deviation and inferential statistics of Analysis of Covariance (ANCOVA) (2-ways) using the difference score method to test the hypotheses for the study at 0.05 level of significance. Where there was any significant F, Scheffé post-hoc analysis was used for further analysis. The result showed that in general, maturation and training accounted for a lot of the differences in the performance of the study groups. There was no significant difference in power of pre- and post- menacheal girls as a result of 12 -weeks circuit training programme. The findings also indicated that the main effects of factor A (Status: pre- and post- menarcheal girls) and factor B (Study Conditions: Experimental and Control) were statistically significant. The effects of the training on speed was significantly better for pre-menarcheal girls than for post-menarcheal girls (Post test $9.32 ; 9.56$ ). Subjects in the experimental groups had better power than those in the control groups. The Implications of this study are that exercise training such as the circuit used in this study can make observable differences in speed and power of adolescents. Effective exercise training programmes should therefore be considered as an integral and inevitable aspect of school curriculum.
\end{abstract}

Keywords: pre-menarcheal girls, post-menarcheal girls,

\section{Introduction}

Circuit training is one of the training methods which are a given number of exercises arranged and numbered consecutively in a given area, it is based on sound anatomical, kinesiological and physiological principles designed to increase strength, power, flexibility, quickness and cardiovascular endurance. Howell and Morford (1964) and Hockey (1981) postulated that circuit training provides a strenuous workout entirely suited to an individual's specific needs, existing capacity and rate of adjustment to progressive vigorous exercises. They also stressed the principles of overload and progression. The basic assumption underlying circuit training is that improvement takes place either by doing the same amount of work in a shorter period of time or by doing more work in a given time. Circuit training utilizes three variables of load, repetitions and time, and this places it on an advantage over other training methods. 
Menarche occurs when adolescent growth is nearly at its peak, or about the middle of puberty proper and one expects growth in height to decelerate rapidly after it has occurred. Menarche may be delayed, or the periods may be scanty or irregular, without indicating that the ovaries are not developing satisfactorily. Such irregularity suggests only that the necessary hormonal balance had not become sufficiently stabilized (Stuart and Prugh, 1974). They also reported that the average age of menarche differs some-what between populations or countries and among the same populations.

In the United States, the average age for menarche is 13 years of age, with a range of 10 to 17 years of age. According to Sinclair (1978), age at which menarche occurs is found to be more closely related to the radiological age than to the chronological age. So, menstruation nowadays begins within a chronological age range of 10 to 16 years, but within a much narrower range of radiological age from 12 to $14 \frac{1}{2}$ years, round about the time of fusion of epiphyses of terminal phalanges of fingers. Within any comparable population group, there are undoubted familial tendencies to be near average, advanced, or late in appearance of this development of chronic illness, and other environmental factors (Stuart and Prugh, 1974).

Bailey, Malina and Rasmussen (1978) stated that physical activity is only o many factors that may affect the growing child and that a significant amount of knowledge on the effects of physical activity on the developing organism is derived by extrapolation from studies of experimental animals. The evaluations of physical growth have relied on application of anthropometric techniques.

Speed is the rate of motion or velocity of the body or any of his part (Wilmore, 1977). It is one of the factors that are critical to skillful performance in various activities. Speed can be measured in a number of ways ranging from simple timing procedures that require elaborate and expensive equipment. It could be measured by the Laboratory method or the field method. The laboratory method includes the use of Cinematography and timing device while the field methods include the use of the 50-yards dash or sprint and 100 meter dash. According to Baumgartner and Jackson (1995), most motor ability or motor fitness batteries recommended 50-yard sprints, while 40-yard sprints are universally accepted by football coaches.

Research studies have shown that speed can be improved through a variety of training programmes. For example, Meadows (1959) and Johnson (1964) found that both Isotonic and Isometric exercises improved speed of movement. Haywood (1986) posited that measures of anaerobic power, such as 50-yard dash performed show a steady improvement in children with increasing age, and consequently body size. Fox and Mathews (19810, Nwankwo (19880 and Bulugbe (1991) reported improvement in running speed as a result of interval training.

According to Klafs and Arnhein (1981) age is one of the factors to be considered for speed attainment. Measures of speed in girls are superior in those who show late maturation (Malina, Harper, Avent et al. 1973). Carron, Aitken and Bailey (1977) stated that in final phase of development (age 16-18 years) girls with a delayed menarche have scores for running speed of limb movement that are superior to those of contemporaries with an early menarche.

Power is identified by Johnson and Nelson (1974) as the ability to release maximum force in the fastest possible time, the exhibition of which can be shown in the vertical jump, the broad jump, the shot put and any other movement against a resistance in the minimum time. Wilmore (1977) found age, height and weight to be of little value for classifying individuals for athletic performance. Jensen and Fisher (1979) postulated that the best approach for increasing power is to increase strength. The speed component of power can be improved by increasing the movement. Baumgartner and Jackson (1995) reported that the need for leg strength in jumping is self-evident and body weight is negatively correlated with jumping ability. This relation could be largely traced to body fatness. Jumping ability depends on individual differences in leg strength and body composition. They also opined that if two individuals can generate the same amount of force, all other things being equal, the leanest person would jump highest

The purpose of this study was to investigate the comparative effects of 12-weeks circuit training programme on seed and of pre-and post- monarcheal girls. 


\section{Hypotheses}

The following hypotheses were tested for the study:

1. There would be significant difference in the speed of pre- and post-monarcheal girl as a result of circuit training programme

2. There would be no significant difference in the power of pre- and post- menarcheal girls as a result of circuit training programme

\section{Methods}

The research design for this for this study was pre-test, post-test control group experimental design with random assignment into groups. The design helps to control for subject selection bias and also affords comparison between the control group and experimental group it also helps to ascertain if treatment really had effect on the experimental group.

The populations for this study were student of St. Peter' College, Olomore, Abeokuta in Ogun State of Nigeria. They were between 10 and17years and were those students that were not in school sports.

The study sample consisted of 80 girls who were apparently healthy. The subjects were screened by taking their relevant medical history and examining their physical health status. This was done by a physician. Those who were found to be free from conditions that could be aggravated by physical activity completed the informed consent form. The inform consent form was to inform all subjects about the nature of the training programme and the tests before the commencement of the measurements.

After signing the informed consent form, the subjects were selected by simple random sampling technique into experimental and control groups. Each of the two groups was also sub-divided into pre- and post- menarcheal groups using the information collected from the pre-exercise questionnaire that was distributed to the subjects.

There were 40 subjects in the experimental group that is 20 pre-menarcheal and 20 postmenacheal girls. The control group also consisted of 40 subjects (20 pre-menarcheal and 20 postmenarcheal girls). The 4 group took part in pre- and post-training measurements while the experimental groups alone were involved in the 12-weeks circuit training programme. Only 40 subjects completed the post-training measurement. This was due to subject mortality.

\section{Procedure for Data Collection}

All measurements and data collection too place at St. Peter's College, Olomore, Abeokuta, Ogun State, Nigeria. Research assistants and Physical and Health Education teachers in the College helped to record and observe the subject. The baseline measurements served as the pre-test while the measurements taken at the end of the pre-test while the measurements taken at the at the end of the training served as the post-tests. Demonstration was given by the researcher where necessary. The following procedures were adopted of the various measurement and test:

1. Age: This was recorded in years.

2. Weight: The subject's body weight was measured using the bathroom weighing scale (Hanson Model). The subject dressed in sports pant barefooted with face forward. The readings were taken to the nearest 0.1 centimetre.

3. Speed: 50 yards dash was used to measure speed. Reliability: The test-retest reliability coefficient of 0.86 was obtained for this test by the researcher. Equipment: Stop watch, whistle and a suitable running area to allow the 50-yards run plus extension for stopping was required. Procedure: The subject was in a ready position with one foot just behind the starting line. The commands "Ready" and "Go" were given. At the command to go the starter dropped her arm so that the timer at the finish line could start the timing. The subject ran as fast as possible across the finish line. Scoring: The elapsed time, from the starting signal until the runner crossed the finish line was measured to the nearest tenth of a second. 
4. Power: Standing Broad jump was used to measure the athletic power of the legs in jumping forward.

Reliability: The reliability reported was as high as 0.963 (AAPHER, 1965).

Validity: A validity of 0.607 was reported for this test when a pure power test was used as the criterion (AAPHER, 1965).

Equipment and Materials: The floor was used for this test. Chalk was needed for the starting line, along with a tape measure to mark off increments of distance along the landing area.

Procedure: The subject stands with her feet at comfortable distance apart and her toes just behind the take-off mark. She crouched, leaned forward, swung her arms backwards and then jumped horizontally as far as possible, jumping from both feet and landing on both feet. The measurement to the nearest centimetre was taken from the take-off mark to the nearest point where the subject touches the floor at the completion of the jump. Each subject was allowed three trials. The best of the three jumps was recorded.

\section{Pilot Study}

A pilot study was carried out to enable the researcher acquaint herself with the test instruments, standardize procedures, establish the feasibility of the study and the other requirements of the study. The pilot study was also carried out to determine the number of research assistants required for the study so that the data would be collected more efficiently.

The sample for the pilot study was taken from students of Ebenezer Grammar School, Iberekodo, Ogun State of Nigeria. Ten students were selected for the pilot study.

\section{Procedure for Training Programme}

The physical activity programme consisted of twelve weeks of aerobic exercises (circuit exercises) three times per week for 1 hour between 7.00a.m. and 8.00a.m.on the school playing ground. The exercises were graduated from week 1 to week 12 by increasing the speed, resistance, duration and intensity. The exercise training was done in a circuit with instructions and supervisions by the researcher and her trained assistants.

Before the commencement of the training programme, pre-exercise observations of the subjects were carried out. A training session usually began with jogging round the field twice and this was followed by warm-up exercises for 10 minutes before the circuit training programme began.

The circuit training programme was performed for 45 minutes and the cool-down activities were for 5 minutes.

The intensity of each exercise started at $60 \%$ heart rate maximum and gradually increased to $90 \%$ before the end of the 12 weeks period. This is in accordance with the recommendation of the American College of Sports Medicine (1986) that recommended an exercise intensity of between $60-90 \%$ of maximal heart rate. The exercise intensity is as shown below. This was strictly followed. It was a guide and depended on the subject's responses.

\begin{tabular}{lccc}
\hline Weeks & Exercise Durations & Intensity & Frequency \\
\hline $1 \& 2$ & 25 minutes & $60-65 \% \mathrm{HRM}$ & 3 days/week \\
$3 \& 4$ & 30 minutes & $65-70 \% \mathrm{HRM}$ & “ \\
$5 \& 6$ & 35 minutes & $70-80 \% \mathrm{HRM}$ & “ \\
$7 \& 8$ & 40 minutes & $80-85 \% \mathrm{HRM}$ & “ \\
$9 \& 10$ & 45 minutes & $80-85 \% \mathrm{HRM}$ & “ \\
$11 \& 12$ & 45 minutes & $85-90 \% \mathrm{HRM}$ & "
\end{tabular}

The warm up activities include: Running on the sport, arm circling, skip jump, astride jumping, one knee raising and pressing to the chest with assistance of hands (lift/ press/lower), through vault in threes, free walking, kicking out-stretched hand with one foot every third step and back pushing. 
All subjects in the experimental group (that is, 20 pre-menarcheal girls and 29 post-menarcheal girls) were divided into 5 groups ( 8 subjects in each group). These groups were performing at the different circuit training stations. Each group of subjects worked at each station worked at each station and had 1 minute of rest before changing to the next station. The subjects moved to the stations in a clockwise direction as soon as the time allotted to each station was over, they were required to go through the 5 stations of the circuit three times. During the rest periods, subjects engaged in breathing exercises. Standing or walking around as the programme progresses.

The circuit training programme consisted of the following: station 1: Rope Skipping: Station 2: Push-ups: Station 3: Step-ups: Station 4: bent-knee sit-ups; Station 5: Burpee.

At the end of the circuit training programme, subjects were given cool down activities.

\section{Results}

The mean age of the pre-menarcheal girls is 13.7 while that of the post-menarcheal girls is 15.3 .

\section{Hypothesis 1}

There would be no significant difference in the speed of pre- and post-menarcheal girls as a result of training programme.

Table 1 Summary of two-way ancova on speed

\begin{tabular}{crrrc}
\hline Source & \multicolumn{1}{c}{ SS } & df & \multicolumn{1}{c}{ Ms } & F------------ \\
\hline A & 29.86 & 1 & 29.86 & $20.45^{*}$ \\
B & 6.08 & 1 & 6.08 & $4.16^{*}$ \\
AB & 1.25 & 1 & 1.25 & 0.89 \\
S/AB & 51.25 & 35 & $1.46 \ldots \ldots \ldots \ldots \ldots \ldots$ \\
\hline & $* \mathrm{p}<.05$ & \multicolumn{3}{r}{ Table value $=4.08$}
\end{tabular}

The 50 yards dash was used to measure speed of the subjects. The lower the time spent in covering distance, the greater the effects of the training on speed. The data in Table 1 reveals that the main effects of factor A (Status: Pre- and Post-menarcheal girls) and factor B (Study Condition: Experimental and Control) were statistically significant $\left(\mathrm{F}_{1,35}=20.45: \mathrm{p}<.05, \mathrm{~F}_{1,35}=4.16 ; \mathrm{p}<.05\right)$. The interaction effect $(\mathrm{A} \times \mathrm{B})$ was not significant. The effects of training on speed were significantly higher for pre-menarcheal girls. With reference to study condition, the training increased the speed of pre-menarcheal subjects (Table 2). Therefore, hypothesis 1 was rejected.

Table 2 Mean and Standard Deviations Scores of Dependent Measures

\begin{tabular}{|c|c|c|c|c|c|c|c|c|c|}
\hline \multirow[t]{2}{*}{$\begin{array}{l}\text { Dependen } \\
\text { t variables }\end{array}$} & & \multicolumn{2}{|c|}{$\begin{array}{c}\text { Pre-Menarcheal } \\
\text { Experimental } \\
(\mathrm{N}=10)\end{array}$} & \multicolumn{2}{|c|}{$\begin{array}{l}\text { Pre-Menarcheal } \\
\text { Control }(\mathrm{N}=10)\end{array}$} & \multicolumn{2}{|c|}{$\begin{array}{c}\text { Post-Menarcheal } \\
\text { Experimental } \\
(\mathrm{N}=10)\end{array}$} & \multicolumn{2}{|c|}{$\begin{array}{c}\text { Post-Menarcheal } \\
\text { Control }(\mathrm{N}=10)\end{array}$} \\
\hline & & Mean & SD & Mean & SD & Mean & SD & Mean & SD \\
\hline \multirow[t]{2}{*}{ Speed } & Pre-test & 10.82 & 0.95 & 10.80 & 2.33 & 11.08 & 1.48 & 10.68 & 1.61 \\
\hline & Post-test & 8.85 & 1.50 & 9.78 & 2.28 & 9.38 & 1.05 & 9.74 & 1.38 \\
\hline \multirow[t]{2}{*}{ Power } & Pre-test & 1.57 & 0.19 & 1.63 & 0.21 & 1.68 & 0.26 & 1.55 & 0.16 \\
\hline & Post-test & 1.90 & 0.21 & 1.64 & 0.21 & 1.72 & 0.24 & 1.58 & 0.17 \\
\hline \multirow[t]{2}{*}{ Weight } & Pre-test & 33.15 & 5.90 & 31.40 & 8.71 & 47.15 & 6.41 & 45.70 & 5.40 \\
\hline & Post-test & 35.50 & 5.04 & 33.20 & 7.25 & 47.20 & 6.35 & 46.00 & 5.56 \\
\hline
\end{tabular}




\section{Hypothesis 2}

There would be no significant difference in the power of pre- and post-menarcheal girls as a result of circuit training programmes.

Table 3 Summary of Two-Way Ancova on Power

\begin{tabular}{ccccccc}
\hline Source & SS & df & MS & F & s/n............ \\
A & 0.18 & 1 & 0.18 & 0.69 & $\mathrm{~ns}$ \\
B & 0.28 & 1 & 0.28 & 1.04 & $\mathrm{~ns}$ \\
AB & 0.21 & 1 & 0.21 & 0.78 & $\mathrm{~ns}$ \\
S/AB & 9.38 & 35 & $0.27 \ldots \ldots \ldots \ldots \ldots \ldots \ldots . .$.
\end{tabular}

The standing broad jump test was used to measure power. The training programme was expected to improve spring in the ankles and thereby improve power. The pre-menarcheal girls had higher performances than the post-menarcheal girls after the training programme (post-test $1.77 ; 1.65$ ). However, the difference was not statistically significant. The girls in the experimental group performed higher and better than those in the control group (pre-test 1.81: 1.61). Again, the differences were not statistically significant. (See Table 2 above). Therefore hypothesis 2 was accepted.

\section{Discussions}

In this study the pre-menarcheal girls were faster than the post-menarcheal girls at the end of the circuit training programmes. This was unexpected and it was contrary to the finding of Klafs and Arnhein (1981) who reported that age is one of the factors to be considered for speed attainments. With exercise the speed of the subjects (pre-menarcheal and post-menarcheal) in the experimental groups improved significantly. This finding was similar to those of Meadows (1959), Johnson (1964) and Haywood (1986) who reported that speed improved through a variety of training programmes. The authors thereafter postulated that measures of anaerobic power, such as 50-yard dash performance show a steady improvement in children with increasing age. The control groups irrespective of status (pre-and post-menarcheal girls) were slower in speed test than the experimental groups. This was expected, since training improves speed as stated by Fox and Mathews (1981) and Nwankwo (1981).

The pre-menarcheal girls showed higher power performance than the post-menarcheal girls. This was unexpected. The result of this study is in line with that of Wilmore (1977) who found that age, height and weight are of little value for classifying individuals for athletics performance. In the present study, one would have expected the post-menarcheal girls to perform better in power than the pre-menarcheal girls if maturation alone is the most important criterion for classifying individual's athletic performance. The result of this study tend to support those of Espenschade (1940) and Clarke (1971) who found that motor performance of adolescent girls was who found that motor performance of adolescent girls was poorly related to maturity status.

The experimental subjects in this study also had higher power performance than the control subjects. The result of this study shows that with training, explosive power of the leg could be improved considerably.

\section{Summary, Conclusions and Recommendations}

The purpose of this study was to determine the comparative effects of circuit training programme on speed and power of pre- and post-menarcheal girls.

The subjects for this study were 80 secondary school girls from St Peter's College, Olomore, Abeokuta, Ogun State of Nigeria, ages 10-17 years. The subjects were not involved in any competitive school sports. All the subjects signed the informed consent form and were selected by simple random sampling techniques into experimental and control groups. Each of the two groups was also sub-divided into pre- and post-menarcheal girls using the information collected from the pre-exercise questionnaire that was given to the subjects to complete. 40 subjects completed the 
programme due to subject mortality. Some of the subjects left for their holidays before the school closed for the term.

A pre-test-post-test control group experimental design was used to carry out the study. The dependent variables of interest in this study were speed, power and weight. Speed was assessed by performance in a 50-yard dash race while power was assessed with the standing broad jump.

The physical activity training programme consisted of 12-weeks of aerobic exercises (circuit training) three times per week for 1 hour between $7 \mathrm{a} . \mathrm{m}$. and $8 \mathrm{a} . \mathrm{m}$. on the school playing ground. The exercise training was done in a circuit with instructions and supervision by the researcher and her training assistance. Subjects in the experimental group (pre-menarcheal and post-menarcheal girls) took part in the training programme. Pre-test measures were taken for all subjects before the training programme started while the post-test measure were taken at the end of the training programme.

The pre- and post-test scores for each subject and for each dependent variable were used in various statistical analyses. A two-way analysis of covariance (ANCOVA) was utilized to analyze the data and to test the hypotheses. Where there was a significant F-test, Scheffé post-hoc and simple main effect analyses were used for further analyses. The significance level for all statistical analyses was set at 0.05 .

There was no significant difference in the power of pre-and post-menarcheal girls as a result of 12weeks of circuit training programme. The pre-menarcheal girls in the experimental group had better speed than the post-menarcheal girls. Irrespective of the treatment condition, the premenarcheal girls were faster in speed than the post-menarcheal girls. The difference in speed was significant for the subjects in the experimental group and not for those in the control group. The pre-menarcheal girls in both the experimental and control groups had slightly better power performance than the post-menarcheal girls. The experimental group irrespective of the status (preand post-menarcheal girls) had higher power performance than the control group.

Based on the findings and limitations of this study, the following conclusions were made:

1. Circuit training programme undertaken three times a week for 12 -weeks did improved the speed and power of pre- and post-menarcheal girls who participated in the study. Therefore, a general statement can be made that regular participation in circuit training can improve speed and power of pre-and post-menarcheal girls.

2. Post-menarcheal girls were better than the pre-menarcheal girls in weight. Therefore, it may be stated that all things being equal, weight may increase to some extent with maturity.

Based on the results of this study, the following recommendations are made:

1. To improve the speed and power of pre- and post-menarcheal girls, one has to subject them to physical activities or exercises. This must be done regularly, about 3 times a week, and the duration of the physical activities or exercises should be long enough (about 15 to 60 minutes depending on the intensity) and be specific in order to obtain the desired effects.

2. Physical activity participation should be optimized in the development of female subjects so that when they grow up, regular participation in physical activities will become an integral part of their lives. This is to contribute to a healthy way of living in general and improve speed and power in particular. In order to have wide spread opportunities to encourage females to participate in physical activities as suggested above, there is great need for government agencies, private individuals and organizations to find and support productive physical activity programmes in which females can participate.

3. In conducting exercise programmes that aimed at influencing the speed and power of youths, effort should be made to control any other variable that may influence the results. Some of the factors are the dietary habits and extra-curricular activities of subjects. 


\section{References}

AAHPER (1965). AAHPER Youth Fitness Test Manual Revised. Washington,D.C.: American Association for Health Physical Education and Recreation. Pg.20.

Bailey, D. A., Malina, R. M. and Rasmussen, R. L. (1978). The Influence of Exercise, Physical Activity, and athletic Performance on the Dynamics of Human Growth. In Faulkner and Tanner, J. M. Human Growth 2 Postnatal Growth. New York: Plenum Press.

Baumgartner, T. A. and Jackson, A. S. (1995). Measurement for Evaluation in Physical Education and Exercise Science $5^{\text {th }}$ Edition. Madison, Wisconsin: WCB Brown And Benchmark Publishers.

Bulugbe, T. A. (1991). Effects of A-6 week interval Training Programme on Running Speed of College Male Track-Athletes. In Amusa, L. O. (ed.)_Sports Science and Medicine 1. 85-90.

Carron, A. V., Aitken, E. J., Barley, D. A. (1977). The relationship of menarche to Growth and development of strength, in Lavellee, H.,Shepard, R. J. (ed.). Frontiers Of Activity and Child Health. Quebec City: Edition du Pelican.

Clarke, H. H. (1971). Physical and Motor Tests in the Medford Boys' Growth Study. New Jersey: Prentice Hill.

Espenschade, A. (1940). Motor Performance in Adolescence. Monogram. Soc. Res. Child Dev. 5(24). 1-126.

Fox, E. L. and Mathews, D. K. (1981). The Physiological Basis of Physical Education And Athletics. $3^{\text {rd }}$. Ed. Philadelphia: Saunders College Publishing.

Haywood, K. M. (1986). Life Span Motor Development. U. S. A.: Human Kinetics Publishers, Inc.

Hockey, R. V. (1981). Physical Fitness: The Pathway to Health. St. Louis: C. V. Mosby Company.

Howell, M. L., and Morford, W. R. (1964). Circuit Training for College Fitness Programme. JOPUER. Feb. pp.30-33.

Jensen, R. C. and Fisher, A. G. (1979). Scientific Basis of Athletic Conditioning $2^{\text {nd }}$. Ed. Philadelphia. Lea and Febiger.

Johnson, B. L. (1964). A Comparison of Isometric Exercises upon the Improvement of Velocity and Distance as Measure by Rope Climb Test. (Unpublished Study, Louisiana State University).

Klafs, C. E. and Arnhein, D. D. (1981). 'Psychogenic Factors in Sports.' Modern Principles of Athletics Training. $5^{\text {th }}$ Edition. London: C. V. Mosby Company.Pg.168-178.

Malina, R. M., Harper, A. B., Avent, H. H., and Campbell, D. E. (1973). Age at Menarche in Athletes and Non-athletes. Medicine and Science in Sports 5(1): 11-13.

Meadows, P. E. (1959). The Effect of Isotonic and Isometric muscle contraction Training On Speed, Force and Strength. (Micro carded Doctor's Dissertation, University of Illinois).

Nwankwo, E. I. (1988). The effect of different training techniques on selected Determinants of physical performance capacity. Journal of National Association of Sports Science and Medicine 2: 109-119.

Sinclair, D. (1978). Human Growth after Birth. $3^{\text {rd }}$. Ed. London: Oxford University Press.

Stuart, H. C. and Prugh, D. G. (1974). The Healthy Child, His Physical, Psychological, And Social Development. U. S. A.: Harvard University Press.

Wilmore, J. H. (1977). Athletic Training and Physical Fitness. Boston: Allyn and Bacon, Inc. 